\title{
Benteng Balangnipa Di Kabupaten Sinjai, Sulawesi Selatan (Pola Tata Ruang Dan Arti Penting Kedudukannya)
}

\section{Sarjiyanto}

Keywords: military archaeology, architecture, fort, dutch, history, indonesia

\section{How to Cite:}

Sarjiyanto, nfn. (2002). Benteng Balangnipa Di Kabupaten Sinjai, Sulawesi Selatan (Pola Tata Ruang Dan Arti Penting Kedudukannya). Berkala Arkeologi, 22(1), 81-95. https://doi.org/10.30883/jba.v22i1.852

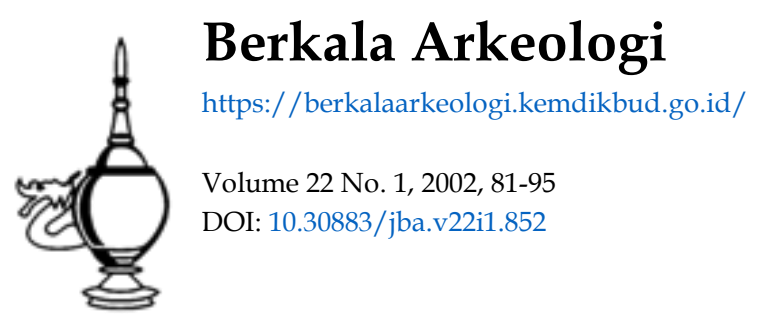

\section{c) (7) (2)}

This work is licensed under a Creative Commons Attribution-NonCommercial-ShareAlike 4.0 International License. 


\title{
BENTENG BALANGNIPA DI KABUPATEN SINJAI, SULAWESI SELATAN (POLA TATA RUANG DAN ARTI PENTING KEDUDUKANNYA)
}

\author{
Sarjiyanto \\ (Pusat Penelitian Arkeologi)
}

\section{Pengantar}

Di bumi Nusantara ini banyak tinggalan arkeologi berupa benteng. Termasuk benteng bercorak kolonial, seperti benteng Speelwijk (Jawa Barat), Vredenburg (Yogyakarta), Benteng Pendem (Jawa Tengah), benteng Malborough, Fort York (Sumatra), Fort Oranje (Ternate), Fort Rotterdam, Balangnipa (Sulawesi). Adapun fungsi benteng dapat bersifat single main function (politik-pemerintahan) maupun multi main function (pemerintahan, perdagangan / pelabuhan). Disamping fungsi penunjang sebagai gudang logistik, kamp tawanan, tempat pendidikan-pelatihan, pengawasan dan lain-lain (Abbas, 1996).

Benteng Balangnipa secara administratif berada di dusun Tokinjong, Kelurahan Balangnipa, Kecamatan Sinjai Utara, Kabupaten Sinjai, $\pm 233 \mathrm{Km}$. dari Kodya Makassar Sulawesi Selatan. Keletakannya menghadap utara ke arah sungai Tangka yang bermuara di Teluk Bone. Berdasarkan ciri morfologisnya, daerah ini terletak di bagian timur Gunung Lompobattang dengan morfologi $80 \%$ terdiri dari medan berbukit dan bergelombang sampai bergunung. Sungai terpanjang dan terbesar yang melewati daerah Sinjai adalah sungai Tangka. Sungai ini memiliki panjang $120 \mathrm{Km}$. dan lebar 1-75 meter menghubungkan wilayah teluk Bone yang strategis dengan daerah pedalaman.

Balangnipa dari segi etimologi berasal dari kata balang dan nipa. Balang berarti lumpur dan nipa berarti pohon nipah. Satu petunjuk mengenai kondisi lingkungan benteng saat itu. Sinjai berasal dari nama perkampungan tua di daerah Bulo-Bulo dari bahasa Makassar yang berarti sama banyak. Saat ini lingkungan sekitar benteng Balangnipa sudah penuh dengan perumahan penduduk. Sungai Tangka di depan benteng sudah mengecil alirannya. Ini disebabkan bendungan yang dibangun Belanda di kampung Tepoe (tepoe $=$ di tutup) desa Tunimbalo (tunimbalo=batu yang ditata) telah bobol tahun 1959. Sisa bendungan masih tampak jika air sungai surut. Hanya perahu kecil yang dapat masuk mendekati benteng sampai di kampung Lappa \pm 500 meter sebelah timur benteng.

Dalam tulisan ini akan diungkap beberapa hal yang mendasari keberadaan dan peranan benteng Balangnipa di daerah Sinjai. Benteng bercorak kolonial yang dibangun pada abad XIX ini merupakan satu diantara benteng yang relatif masih utuh di Sulawesi 
Selatan. Informasi dihimpun dari studi kelayakan tahun 1985/86 oleh SPSP Sulselra dan penelitian tahun 1997 oleh Balai Arkeologi Makassar.

\section{Benteng Balangnipa}

\section{A. Data Bangunan}

Secara keseluruhan luas kompleks benteng Balangnipa $\pm 2.500 \mathrm{M}^{2}$. Dengan luas demikian, benteng hanya mampu memuat beberapa bangunan. Denah benteng berbentuk segi empat dengan bastion di setiap sudutnya. Panjang dinding sisi utara $49,45 \mathrm{M}$, sisi barat $49,10 \mathrm{M}$, sisi selatan $30,37 \mathrm{M}$ dan sisi timur 49,27 $\mathrm{M}$ dengan ketinggian $4 \mathrm{M}$ dan ketebalan antara 40-50 $\mathrm{Cm}$. Benteng bercorak kolonial dengan ciri dinding tebal dan tinggi sesuai proporsi tubuh orang Eropa. Bastion sebagai ciri benteng modern (Eropa) memiliki selasar berbentuk bundar. Di bawah selasar terdapat ruang dengan jendela-jendela kecil berjeruji sejumlah 9 buah untuk mengintai keluar.

Di dalam kompleks terdapat beberapa bangunan yang dapat diidentifikasi sebagai bangunan perkantoran, barak, pasukan, gudang amunisi/mesiu, penjara, dapur. Ukuran jendela semua bangunan sama yaitu tinggi $160 \mathrm{Cm}$ dan lebar $140 \mathrm{Cm}$. Sementara pintu bangunan utama dengan tinggi $3,20 \mathrm{Cm}$ dan lebar $142 \mathrm{Cm}$.

\section{Bangunan Perkantoran}

Bangunan yang diduga sebagai perkantoran dilihat dari tata ruangnya yakni bangunan sisi utara yang sebagian dindingnya juga berfungsi sebagai tembok keliling. Bangunan ini berukuran $16 \times 8,50 \mathrm{M}$ dan tinggi $8,50 \mathrm{M}$ tidak termasuk atap. Lantai 2 memiliki 5 kamar, dengan satu kamar semacam serambi. Tangga berada di samping kiri kanan di sisi selatan bangunan. Lantai bawah terdiri 3 kamar di samping kanan kiri lorong pintu utama. Pintu utama memiliki lebar $4 \mathrm{M}$ berbentuk melengkung. Tinggi bagian tengah pintu 4,30 M. Ruang di lantai bawah ini diduga digunakan sebagai gudang logistik.

\section{Bangunan para Komandan/Perwira}

Bangunan di sisi timur kompleks benteng yang berukuran $12 \mathrm{M}$ × $8 \mathrm{M}$ dan tinggi 7,50 M. Bangunan itu diduga merupakan tempat para perwira pasukan. Untuk naik ke lantai 2 melalui tangga melingkar di sisi utara ruang bangunan.

\section{a. Bangunan Barak Pasukan}

Bangunan berukuran $12 \mathrm{M}$ × $8 \mathrm{M}$ berketinggian $8 \mathrm{M}$ ini, terdiri 2 lantai berada di sisi selatan. Masing-masing lantai memiliki 2 kamar besar dan serambi. Ruangan 
dilengkapi fasilitas untuk menaruh senapan dan rak/kapstok untuk perlengkapan perang. Fasilitas itu berbentuk lubang tempat menaruh popor senapan sejumlah 21 buah melingkar pada tiang penyangga atap. Tempat senapan yang masih utuh berada di kamar sisi timur lantai dua, namun sudah di cat baru warna biru bersama tiangnya.

\section{b. Bangunan Gudang Amunisi/Mesiu}

Bangunan yang diduga sebagai gudang amunisi berada di sisi selatan benteng, dengan kondisi rusak parah. Bangunan berukuran 8,20 M x 5,25 $\mathrm{M}$ dan tinggi 4,75 $\mathrm{M}$ dengan atap yang telah hilang. Atapnya semula berbentuk melengkung terbuat dari bahan bata. Lantai terbuat dari papan setinggi $\pm 50 \mathrm{Cm}$ dari permukaan tanah. Namun papan yang dimaksud sudah tidak ada, tinggal bekas lubang tempat memasukkan balok penopang. Konstruksi bangunannya berupa konstruksi batu dari pondasi sampai atap. Bangunan ini sering juga disebut kandang macan. Menurut informan sebagai lambang tawanan kelas berat dengan menempatkan di kolong lantai yang terdapat lubang-lubang angin

\section{c. Bangunan Penjara}

Berdasarkan pengamatan diduga penjara menempati ruang bawah bastion sudut barat daya. Ruang bagian bawah bastion sudut barat daya dilengkapi pintu masuk terbukti masih ditemukan engselnya. Selain itu jendela-jendela kecil yang ada pemasangan jerujinya diperkuat dengan memasang secara tegak dan melintang.

\section{d. Bangunan Dapur}

Ada 2 bangunan dapur disamping kanan kiri pintu utama. Bangunan memanjang arah timur barat dengan ukuran masing-masing $10 \mathrm{M} \times 3 \mathrm{M}$ terbagi 3 petak. Salah satunya memiliki tempat tungku dapur dengan cerobong asap gaya Eropa. Cerobong asap dibentuk semacam atap yang mengecil di atas terbuat dari bahan bata dan semen.

\section{e. Sumur dan Kamar Mandi}

Ada 4 buah sumur di dalam dan 2 buah di luar kompleks benteng. Satu sumur di sudut timur laut dalam kompleks benteng terpotong dinding serambi dapur. Kamar mandi di belakang bangunan perwira yang dipisahkan lorong beratap, serta di ruang di bawah bastion sudut barat laut yang dilengkapi bak mandi besar dan lubang WC.

\section{f. Sisa Pondasi}

Sisa pondasi terdapat di sebelah barat bangunan barak pasukan. Pondasi ini sejajar dengan bangunan barak. Menurut keterangan informan merupakan bekas bangunan barak juga. Bangunan ini hancur terkena bom serangan tentara NICA pada waktu yang 
lebih kemudian. Sisa struktur pondasi di sebelah selatan bangunan perwira diduga bekas dapur.

\section{B. Data Artefaktual}

\section{Unsur Bangunan}

a. Ubin

Tabel 1. Identifikasi Ubin

\begin{tabular}{|c|l|l|l|c|c|c|}
\hline Tipe & Ukuran $\mathbf{( C m )}$ & \multicolumn{1}{|c|}{ Inskripsi } & Warna & Asal & Jml & Ket. \\
\hline 1. & $16 \times 16 \times 2$ & $\begin{array}{l}\text { H. VAN VRECKOM } \\
\text { QUA REGNON } \\
\text { BELGIUE }\end{array}$ & Coklat & Belgia & 4 & Utuh \\
2. & $15 \times 15 \times 4$ & $\begin{array}{l}\text { ALFRED REGOLT } \\
\text { \& Co, HOLLAND } \\
\text { MAASTRICHT }\end{array}$ & Coklat & Belanda & 11 & Utuh \\
3. & $15,5 \times 15,5 \times 14,5$ & $\begin{array}{l}\text { F. SCHOLSF A } \\
\text { H. BOSCH \& Co } \\
\text { MAASTRICHT } \\
4 .\end{array}$ & $\begin{array}{l}\text { Coklat } \\
\text { MAASTRICHT } \\
\text { H. BOSCH I }\end{array}$ & Belanda & 17 & Utuh \\
$5.5 \times 15,5 \times 4,5$ & - & Coklat & Belanda & 18 & Utuh \\
\hline
\end{tabular}

\section{b. Bata}

Sebagai salah satu unsur utama konstruksi bangunan benteng tercatat minimal ada 3 ukuran bata. Bata diduga dibuat setempat, seperti telah digunakan juga pada benteng Somba Opu, Makassar yang usianya lebih tua.

\section{c. Genteng}

Atap bangunan di kompleks benteng Balangnipa sebelum dipugar menggunakan genteng yang terbuat dari bahan semacam semen bertuliskan huruf VFS M, yang diduga didatangkan dari Jawa (Batavia). 


\section{Unsur Non Bangunan}

\section{a. Keramik}

Keramik botol berbahan tanah liat ini berwarna coklat dan berglasir, terdiri dari 2 tipe. Menurut keterangan keramik botol ditemukan di dapur sisi barat. Botol-botol ini diduga sebagai wadah minuman beralkohol. Dari botol tipe 2 ada yang memuat angka 1622 mungkin merupakan angka tahun atau nomor produksi.

Tabel 2. Identifikasi Botol Keramik

\begin{tabular}{|c|c|c|c|c|c|c|c|}
\hline \multirow[t]{2}{*}{ Tipe } & \multicolumn{3}{|c|}{ Ukuran (Cm) } & \multirow[t]{2}{*}{ Warna } & \multirow[t]{2}{*}{ Inskripsi } & \multirow[t]{2}{*}{$\mathrm{Jml}$} & \multirow[t]{2}{*}{ Keterangan } \\
\hline & $\mathrm{Tg}$ & Dml & Dmb & & & & \\
\hline 1. & 14 & 2 & 7,5 & Coklat & $\begin{array}{l}\text { SELTER NASAU } \\
\text { Num }\end{array}$ & 9 & $\begin{array}{l}\text { Utuh (6), setengah } \\
\text { utuh (3) }\end{array}$ \\
\hline 2. & 13 & 2 & 8 & Coklat & $\begin{array}{l}\text { APOLINARIS } \\
\text { BRUMNER M-W } \\
\text { EORGKREUZBERG }\end{array}$ & 6 & $\begin{array}{l}\text { Utuh (3), setengah } \\
\text { utuh (3) }\end{array}$ \\
\hline- & - & - & - & Coklat & $\begin{array}{l}\text { EINPREUSSEN } \\
\text { AHRWEILER } \\
-\end{array}$ & - & $\begin{array}{l}\text { Fragmen dasar (1) } \\
\text { Badan (1) Tepian } \\
\text { (10), Leher (3) }\end{array}$ \\
\hline
\end{tabular}

Tg.: tinggi, Dml.: diameter mulut, Dmb.: diameter badan

Ada beberapa bentuk keramik porselin yang ditemukan seperti cawan, mangkuk, piring, vas yang berasal dari beberapa negara. Keramik-keramik ini ditemukan di dekat lubang sampah di sisi selatan benteng.

Tabel 3. Identifikasi Bentuk Keramik

\begin{tabular}{|l|l|c|l|}
\hline \multicolumn{1}{|c|}{ Jenis } & \multicolumn{1}{|c|}{ Bagian } & Jumlah & \multicolumn{1}{|c|}{ Keterangan } \\
\hline Cawan & Tepian, badan, dasar & 14 & Eropa (Belanda) \\
Piring & Tepian, badan, dasar & 7 & Cina (Ming), Eropa \\
Mangkuk (besar) & Tepian, badan, dasar & 11 & Cina (Ming Swatow) \\
Mangkuk (Kecil) & Tepian, badan, dasar & 6 & Cina (Qing), Eropa \\
Vas & Badan bahu & 1 & Vietnam \\
Cangkir & Pegangan & 1 & Eropa \\
Tidak teridentifikasi & Badan & 1 & Eropa \\
\hline
\end{tabular}

\section{b. Mata Uang}

Mata uang ditemukan merata di kompleks benteng. Mata uang tertua tercatat berangka tahun 1744 dan inskripsi HOLANDIA tulisan latin dan lambang kerajaan Belanda bernilai $2 \mathrm{~S}$. Bahan mata uang diduga dari perak. 
Tabel 4. Identifikasi Mata Uang

\begin{tabular}{|c|c|c|c|c|c|c|c|c|c|}
\hline \multirow[b]{2}{*}{ Tipe } & \multirow[b]{2}{*}{ Bahan } & \multicolumn{2}{|c|}{ Na m a } & \multirow[b]{2}{*}{ Gambar } & \multicolumn{2}{|c|}{ Tulisan } & \multirow[t]{2}{*}{ Nilai } & \multirow[t]{2}{*}{$\mathbf{J m l}$} & \multirow[t]{2}{*}{ Ket. } \\
\hline & & $\begin{array}{l}\text { Mata } \\
\text { Uang } \\
\end{array}$ & Tahun & & Huruf & Bahasa & & & \\
\hline Berlubang Bulat & Perunggu & Gulden & 1945 & Padi & $\begin{array}{l}\text { Latin, Jawa } \\
\text { Arab }\end{array}$ & $\begin{array}{l}\text { Belanda } \\
\text { Indonesia }\end{array}$ & $1 \mathrm{G}$ & 26 & Utuh \\
\hline Berlubang Bulat & Perunggu & Gulden & 1912 & Mahkota & $\begin{array}{l}\text { Latin, Jawa } \\
\text { Arab }\end{array}$ & $\begin{array}{l}\text { Belanda } \\
\text { Indonesia }\end{array}$ & $5 \mathrm{G}$ & 2 & Utuh \\
\hline Berlubang Bulat & Alumunium & Sen & 1951 & - & Latin, Arab & Indonesia & $5 \mathrm{Sen}$ & 1 & Utuh \\
\hline Tidak Berlubang & Perunggu & Cent & 1945 & $\begin{array}{l}\text { Lambang Kerajaan } \\
\text { Belanda }\end{array}$ & $\begin{array}{l}\text { Latin, Jawa } \\
\text { Arab }\end{array}$ & $\begin{array}{l}\text { Belanda } \\
\text { Indonesia }\end{array}$ & $21 / 2$ Cent & 44 & Utuh \\
\hline Tidak Berlubang & Perunggu & Cent & 1920 & $\begin{array}{l}\text { Lambang Kerajaan } \\
\text { Belanda }\end{array}$ & $\begin{array}{l}\text { Latin, Jawa } \\
\text { Arab }\end{array}$ & $\begin{array}{l}\text { Belanda } \\
\text { Indonesia }\end{array}$ & 1Cent & 6 & Utuh \\
\hline Tidak Berlubang & Perunggu & Cent & 1945 & Mahkota & $\begin{array}{l}\text { Latin, Arab } \\
\text { Jawa }\end{array}$ & $\begin{array}{l}\text { Belanda } \\
\text { Indonesia }\end{array}$ & $1 / 2$ Cent & 83 & Utuh \\
\hline Tidak Berlubang & Perunggu & - & 17. & $\begin{array}{l}\text { Lambang } \\
\text { VOC }\end{array}$ & Latin & Belanda & - & 2 & Aus \\
\hline Tidak Berlubang & Perak & Stuiver & 1744 & $\begin{array}{l}\text { Lambang Kerajaan } \\
\text { Belanda }\end{array}$ & Latin & Belanda & $2 S$ & 2 & Satu aus \\
\hline Tidak Berlubang & Perunggu & - & - & $\begin{array}{l}\text { Lambang } \\
\text { VOC? }\end{array}$ & Latin & Belanda & - & 2 & Agak aus \\
\hline Tidak Berlubang & Perunggu & Cent & 1857 & $\begin{array}{l}\text { Mahkota Lambang } \\
\text { Kerajaan Belanda }\end{array}$ & $\begin{array}{l}\text { Latin, Jawa } \\
\text { Arab }\end{array}$ & $\begin{array}{l}\text { Belanda } \\
\text { Indonesia } \\
\end{array}$ & $21 / 2$ Cent & 1 & \\
\hline & & & & & & & & 79 & \\
\hline
\end{tabular}




\section{c. Meriam}

Ada dua meriam yang sempat tercatat dalam tulisan ini. Pertama, meriam dengan bentuk laras bulat dari bahan besi ditemukan di selatan kompleks benteng (sekarang tersimpan di dalam benteng). Meriam ini berukuran panjang seluruhnya $124 \mathrm{Cm}$ dengan lubang laras $7 \mathrm{Cm}$. Meriam ini pernah terbakar dalam tempat sampah dan kondisinya sangat aus. Meriam kedua, terletak di dusun Lampe Bosing Kelurahan Lappa di tepi sungai Tangka. Menurut informasi meriam dari bahan besi berukuran panjang $175 \mathrm{Cm}$ dengan diameter lubang laras $12 \mathrm{Cm}$ ini dibeli oleh Aru Lamati dari pihak Portugis untuk menghadang Belanda.

\section{Kaitan Pola Tata Ruang dan Kedudukan Benteng}

Berbagai kepentingan terutama yang bersifat politis, ekonomis mendorong Belanda perlu membangun sebuah benteng di daerah Sinjai. Adapun mengenai tahun pembangunan benteng Balangnipa ada dua versi. Ada sumber yang menyebut tahun 1557, mungkin tahun pertama sekali benteng (masih berupa pos keamanan) dibangun kerajaan Lamati yang letaknya tidak jauh dari lokasi. Sementara sumber lain menyebut tahun 1669 mungkin tahun dimana pos ini mulai dikembangkan menjadi benteng yang lebih kuat oleh Tellung Limpoe aliansi tiga kerajaan Lamati, Tondong dan Bulo-bulo. Tellung berarti tiga dan Limpoe berarti diduduki. Jadi daerah yang dikuasai tiga raja, saat benteng mulai dibangun dari bahan batu karang, batu gunung, pasir dan perekat lumpur. Selanjutnya tahun 1864-1868 (tertulis pada dinding sebelah kanan kiri pintu utama) benteng diubah dengan corak kolonial oleh penguasa Belanda (Hadimulyono, Abdul Muttalib, 1979). Tellung Limpoe banyak memainkan peranan penting di Sinjai. Karena pentingnya wilayah ini, kerajaan Makasar dan Bone senantiasa menjadikannya sumber konfrontasi. Pada awal abad XVIII Sinjai berkembang menjadi lokasi dagang di kawasan teluk Bone.

Ramainya perdagangan sangat memungkinkan berkembangnya beberapa pelabuhan kecil untuk menyalurkan produk pertanian dari pedalaman. Pelabuhan yang pernah berkembang di Sinjai adalah Larea-rea, terletak dekat muara sungai Tangka. Sekarang menjadi pelabuhan kecil untuk penduduk menambatkan perahu ikannya. Di bekas pelabuhan Larea-rea pernah ditemukan keramik asing dinasti Qing, Ming Swato, Jepang, Swankalok dan Eropa. Selain itu ditemukan fragmen meriam yang pecah ketika digunakan. Kemudian pelabuhan Tokinjong yang diduga kuat dulu berada di depan benteng Balangnipa.

Orientasi benteng berdasarkan pengamatan tampak dipengaruhi faktor geoekologi adanya sungai Tangka yang mengalir didepan benteng. Sebagaimana abad-abad sebelumnya, muara sungai menjadi tempat yang berarti bagi tumbuhnya komunitas 
niaga. Kerajaan-kerajaan di Sinjai yang berkembang sejak abad XII semakin memantapkan kedudukannya seiring dengan perkembangan produk pertanian dan semakin ramainya perdagangan pada abad XVIII. Ini tidak terlepas dari upaya pengefektifan subsistensi pertanian dan hortikultura di wilayah pedalaman sungai. Karena alasan itu pula kemudian juga berkembang dua pelabuhan yang berperan di Sinjai yakni pelabuhan Larea-rea dan Tokinjong. Untuk meningkatkan efektivitas dan jaminan keamanan dalam perdagangan, maka dibangun pos keamanan yang nantinya menjadi kompleks benteng Balangnipa

Munculnya benteng Balangnipa dan beberapa benteng bercorak kolonial di lain tempat tidak terlepas dari situasi politik global saat itu. Belanda mulai ikut campur tangan dalam bidang politik setelah berhasil memonopoli bidang ekonomi. Dalam bidang perdagangan Belanda mulai menaruh perhatian pada potensi produk agraris, setelah sebelumnya berhasil menguasai wilayah pesisir dan beberapa daerah pedalaman. Pembenahan sarana pelabuhan dilakukan agar memadai untuk pengangkutan laut yang makin meningkat (Leirissa, 1984). Potensi produk agraris seperti padi yang telah dikembangkan secara intensif oleh pihak kerajaan Gowa di daerah Maros, Siang (Pangkajene) dicoba untuk dimonopoli Belanda. Kerajaan di pedalaman yang mulai berkembang seperti Wajo, Soppeng dan utamanya Bone menjadi ancaman dari arah daratan bagi supermasi kerajaan Makasar dan Belanda sebagai pendatang baru. Kerajaan Bone mulai menanamkan pengaruhnya di beberapa negeri daratan dan pesisir utara dan sepanjang teluk Bone (Mattulada, 1991). Bagi Belanda kerajaan Bone ibarat duri dalam daging karena senantiasa melakukan pertentangan dan mengganggu eksistensinya di wilayah Sulawesi selatan.

Demi kepentingan ekonomi dan alasan politis Belanda mulailah dilakukan penyerangan ke daerah Bone sejak pertengahan Maret tahun 1825. Pasukan lewat jalur darat (Bulukumba-Kajang-Sinjai) dipimpin Moyor Lobron de Vasela, sedangkan jalur laut (teluk Bone) pasukan dipimpin Jendral van Coen. Karena perlawanan gigih dari masyarakat Bone di Sinjai diperparah serangan malaria pada pasukan Belanda, penyerangan gagal membuahkan hasil. Bahkan kapal Belanda Groningen sempat ditenggelamkan. Penyerangan berikutnya Januari tahun 1859 pasukan Mayor Jenderal Steinmetz juga mengalami kegagalam meskipun telah sampai di BajoE. Serangan lebih besar dilakukan Belanda pada Nopember 1859 dipimpin Letnan Jendral I van Zwieten menyerang Balangnipa dan berhasil menguasai. Kapten Wiegend oleh Belanda ditunjuk sebagai Komandan Militer dan Sipil Gezaghebber atas daerah Sinjai berkedudukan di Balangnipa (Abdurrazak, 1989).

Masa penguasaan di Balangnipa ada indikasi Belanda berusaha meningkatkan peranan benteng. Ini terbukti dengan upaya Belanda memperbesar aliran sungai di depan benteng dengan membuat bendungan. Usaha itu mungkin diharapkan agar kapal-kapal yang lebih besar dapat masuk sampai ke depan benteng Balangnipa. Satu sarana 
memudahkan penyerangan ke Bone untuk selanjutnya memantapkan penguasaan pada jalur ekonomi perdagangan. Oleh karenanya didalam benteng terdapat beberapa fasilitas yang dapat mendukung fungsinya sebagai tempat bertahan dan berdagang. $\mathrm{Di}$ dalamnya terdapat bastion, lubang-lubang pengintaian, barak pasukan, gudang amunisi, gudang logistik dan sebagainya. Temuan artefaktual berupa mata uang, keramik asing, meskipun prosentasenya sedikit menunjukkan benteng juga berfungsi untuk kegiatan ekonomi.

Benteng ini secara keseluruhan tidak memasukkan elemen-elemen arsitektur setempat, baik Bugis atau Makassar yang sebelumnya diberitakan pernah ada. Bentuk atap limasan dengan konstruksi tiang kayu. Pengubahan bentuk arsitektur pada kompleks benteng Balangnipa tentunya untuk menunjukkan citra perencana atau pemakai jasa bangunan (Belanda). Pada benteng terdapat bastion sebagai satu ciri benteng modern. Temuan artefaktual seperti botol, piring keramik, mata uang, ubin semuanya menguatkan keberadaan orang Belanda di Balangnipa.

Dalam kompleks benteng yang tidak terlalu luas tercatat hanya ada 4 buah bangunan besar ditambah sebuah bangunan berukuran sedang (gudang amunisi). Bahkan untuk bangunan penjara dan kamar mandi menempati ruang di bawah bastion dan dari segi teknologi terlihat bangunan cukup sederhana. Kondisi ini terkait dengan upaya efisiensi biaya dan tempat. Sarana dan prasarana pemenuhan kebutuhan (pertahanan) dapat terwujud dengan tenaga dan biaya yang tidak sedikit. Oleh karenanya diperlukan upaya konsolidasi dalam hal kemampuan, biaya, teknologi agar tercipta ruang yang efektif dan efisien (Richard C.S, 1968). Kondisi demikian sekurang-kurangnya mengandung dua alasan. Pertama, bagi Belanda Sinjai hanyalah sasaran antara. Target utama serangan adalah menaklukkan kerajaan Bone yang waktu itu mulai kuat dan besar. Dengan demikian pembangunan benteng Balangnipa hanyalah untuk menjadikan lokasi ini sebagai tempat persiapan untuk penyerangan yang lebih besar ke Bone. Kedua, Belanda memang tidak hendak menjadikan benteng Balangnipa sebagai pusat berbagai kegiatan (multi main fuction), sebagaimana dilakukan di Fort Rotterdam, Makassar Karena hal itu akan memerlukan bangunan yang memadai baik dalam kuantitas maupun kualitas.

Kondisi tersebut di atas disebabkan juga, akhir abad XVIII merupakan saat kekuatan Belanda di Indonesia umumnya sedang menurun drastis. Pemerintah Belanda di Eropa dan Indonesia menghadapi ancaman perang dari Inggris. Kondisi ini dimanfaatkan Sultan Bone La Tenritappu (1775-1812) mengekspansi daerah utara Makasar, Noorderdistricten orang Belanda menyebut, seperti daerah Maros, (Siang) Pangkajene, kantong pertanian yang dikuasai Belanda berdasar Perjanjian Bungaya tahun 1667/1669 (Abdurrazak, 1989). Tindakan kerajaan Bone ini sangat ditentang Belanda, yang berusaha menaklukkannya. Walaupun akhirnya Belanda tidak pernah benarbenar berhasil menguasai Bone kecuali terbatas penguasaan pada kontrol perdagangan. 
Laskar Bone pada tahun 1905 mengalami kekalahan ketika Belanda dengan pasukan besar-besaran yang berpangkalan di Sinjai menyerang Bone. Benda-benda Arajang (regalia) kerajaan Bone berhasil diambil alih. Selanjutnya Belanda menyusun pemerintahan baru terdiri dari Afdeling Bone yang terdiri dari tiga daerah (Bone, Wajo, Soppeng). Khusus kerajaan Bone oleh Belanda disebut Onder Afdeling Bone. Laskar Bone mengubah strategi perlawanan dengan perang gerilya. Pemerintah kerajaan Bone (Dewan Arung Pitu) dibekukan sampai tahun 1924 ketika situasi oleh Belanda dirasa aman (Ibid).

\section{Penutup}

Ada beberapa kesimpulan dari uraian yang berkaitan dengan keberadaan Benteng Balangnipa. Kompleks benteng tidak terlalu luas sehingga hanya ada beberapa bangunan utama yang sederhana. Ini berhubungan dengan fungsi, tingkat kebutuhan ruang serta peranan benteng. Kondisi intern Belanda juga sedang mengalami kemerosotan kekuatan dan ancaman dari luar. Tinggalan artefaktual juga menunjukkan peran (Belanda) dalam pemakaian benteng. Pembangunan benteng mempertimbangkan kepentingan ekonomi dengan berusaha menguasai kerajaan Bone, dan teluk Bone yang strategis.

Benteng Balangnipa pernah dimanfaatkan untuk pejuang kemerdekaan RI (angka tahun pada temuan mata uang punya korelasi kuat dalam hal ini), asrama kepolisian, dan saat ini belum dimanfaatkan rencananya untuk museum daerah. Benteng ini terbukti nyata menjadi arti penting khususnya bagi daerah Sinjai dan bagi Belanda ketika hendak menguasai Bone karena kepentingan ekonominya. Tinggalan benteng kolonial yang ada turut memperkaya data sejarah perjuangan bangsa Indonesia, khususnya kerajaan Bone.o 


\section{KEPUSTAKAAN}

Abdurrazak Daeng Patunru, Dkk, 1989. Sejarah Bone, Yayasan Kebudayaan Sulawesi Selatan

Hadimulyono, Dkk, 1979. Sejarah Kuna Sulawesi Selatan, SPSP Sulselra.

Leirissa, R.Z. (Ed.), 1984. Sejarah Nasional Indonesia IV, Jakarta „P.N. Balai Pustaka.

Mattulada, 1991. Menyusuri Jejak Kehadiran Makasar Dalam Sejarah, Hasanuddin University Press.

Muhaeminah, Sarjiyanto, 1997. "Benteng Kolonial Belanda di Balangnipa, Kabupaten Sinjai", Laporan Penelitian, Balai Arkeologi Ujung Pandang, 1997

Novida Abbas, 1996. "Penempatan Benteng Kolonial di Kota-kota Abad XVII-XLX M di Jowa Tengah", EHPA Ujung Pandang 20-26 Sept.

Richard C.S, Thomas S, 1968. The Geography of Economic Activity, $\left(2^{\text {nd }}\right)$, New York: M.C. Hill.

Tim Penyusun, 1985/86. Studi kelayakan Benteng Balangnipa di Kabupaten Sinjai, Sulawesi Selatan, Proyek Pemugaran dan Penelitian PSP, Depdikbud Ujung Pandang. 


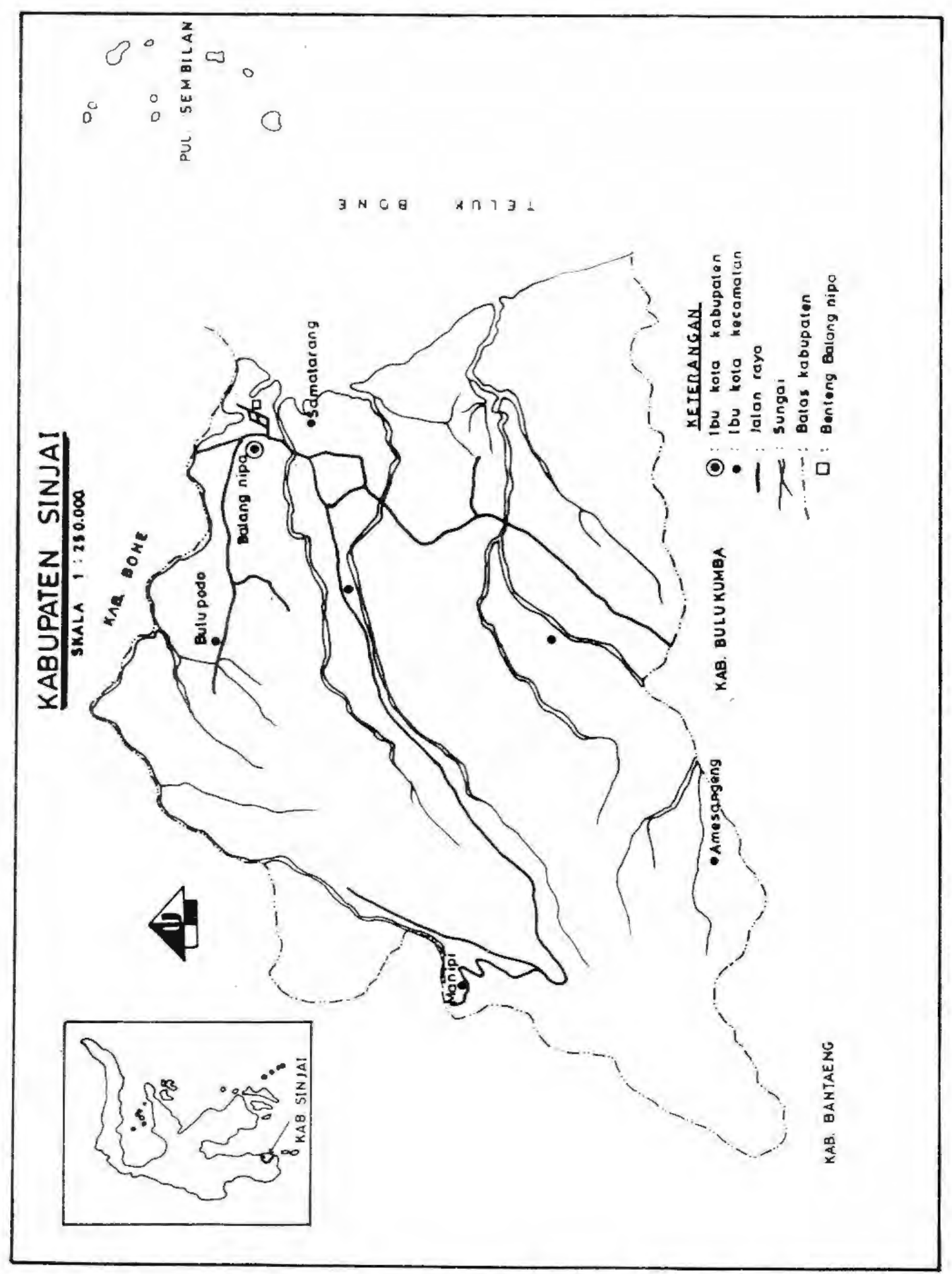




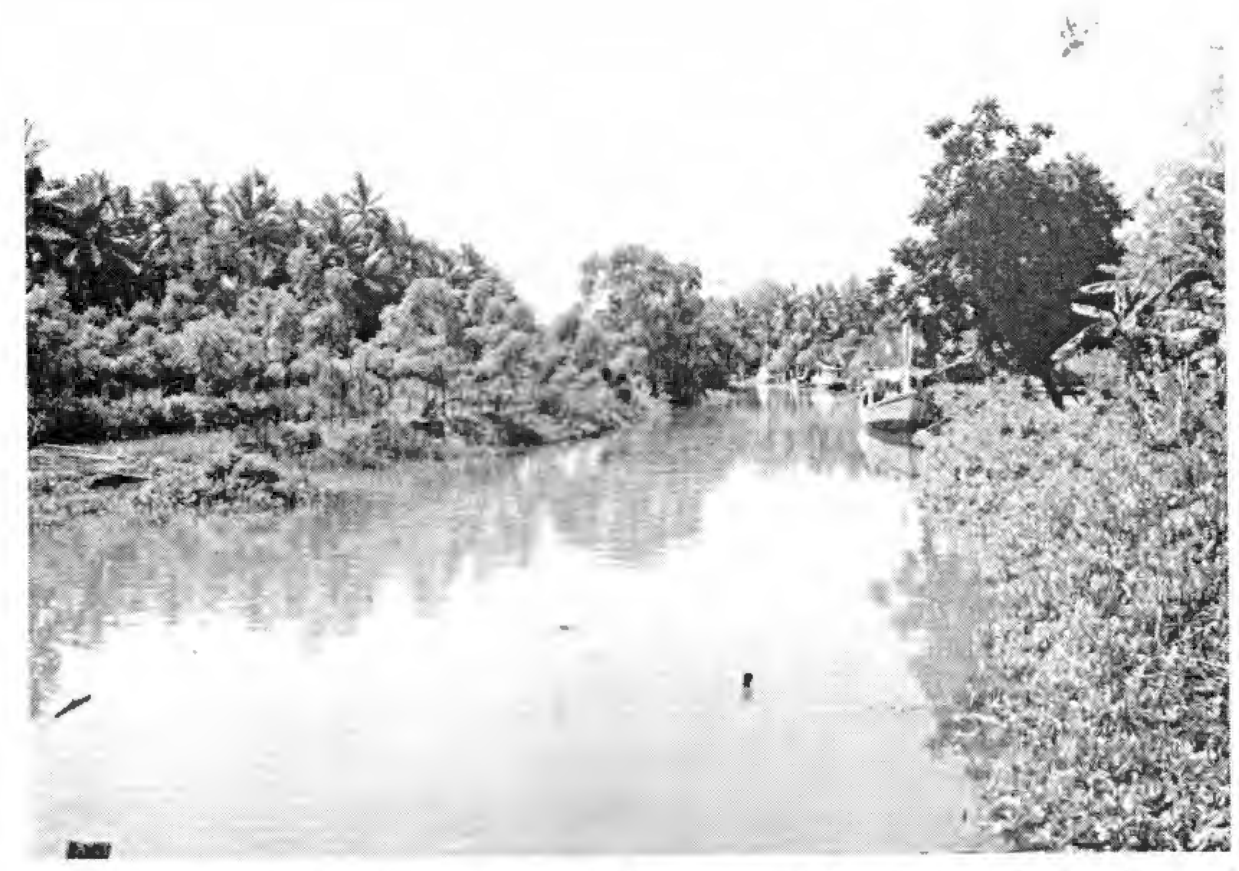

1. Situasi sungai di utara benteng Balangnipa. Beberapa perahu kecil masih dapat masuk sampai sejauh \pm 500 meter dari benteng di kampung Lappa.

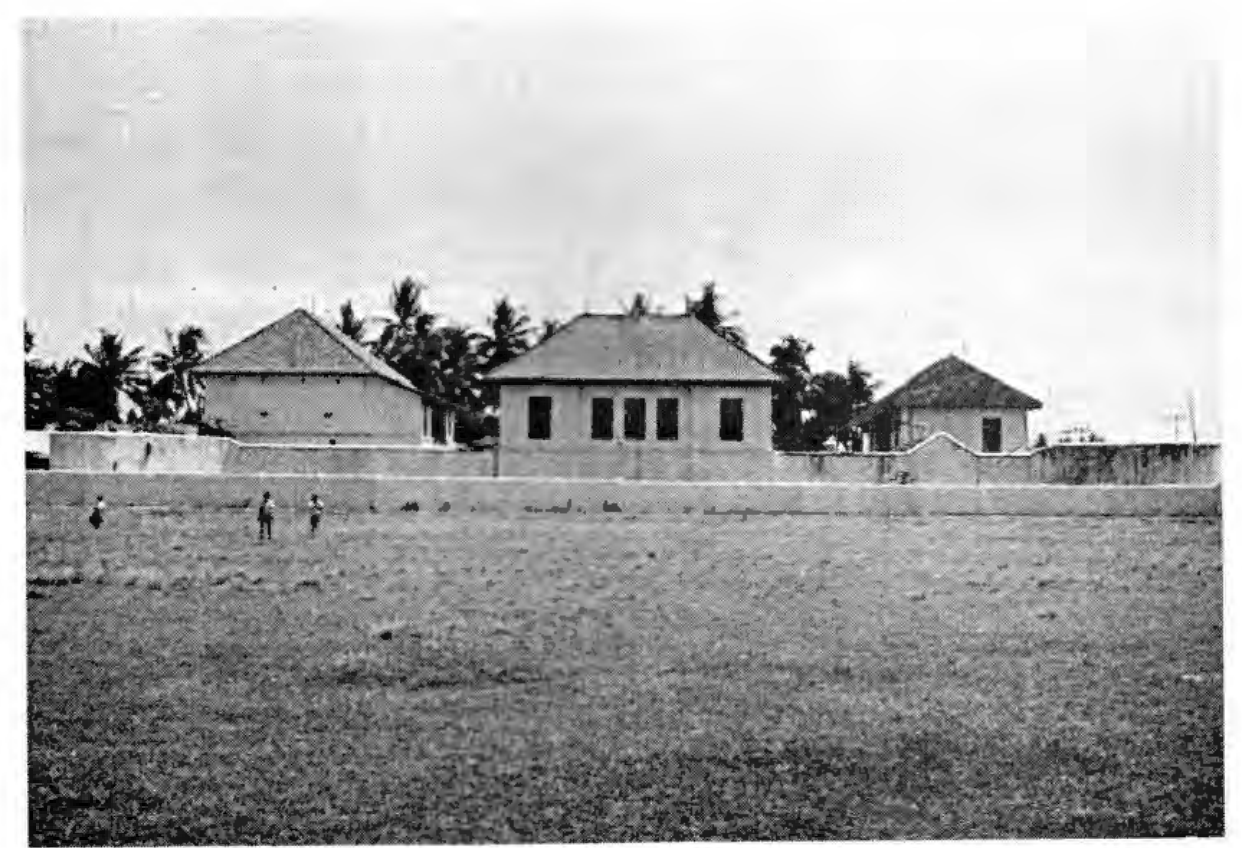

2. Benteng Balangnipa dilihat dari luar. Tampak tanah lapang di sebelah timur benteng. 


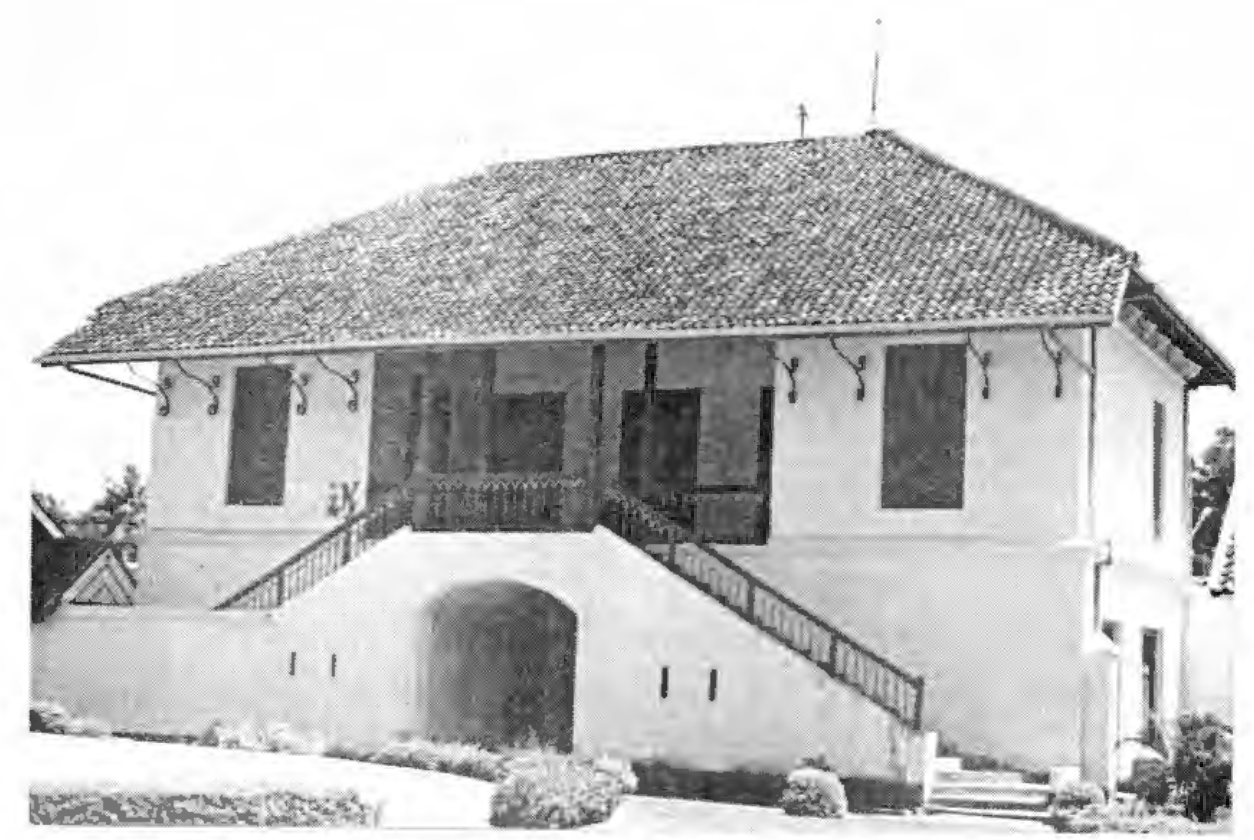

3. Salah satu bangunan (perkantoran) dalam kompleks benteng Balangnipa.

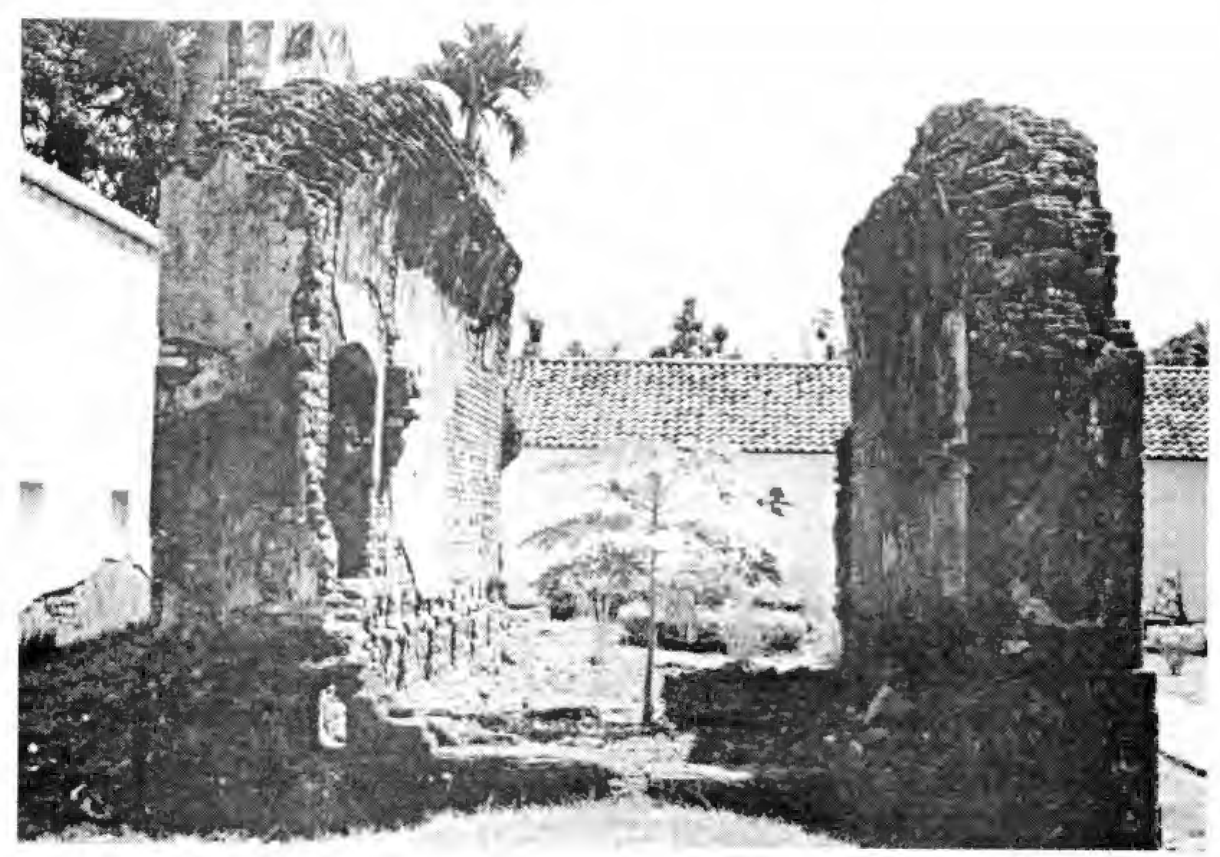

4. Kondisi bangunan gudang amunisi yang sudah rusak parah. 


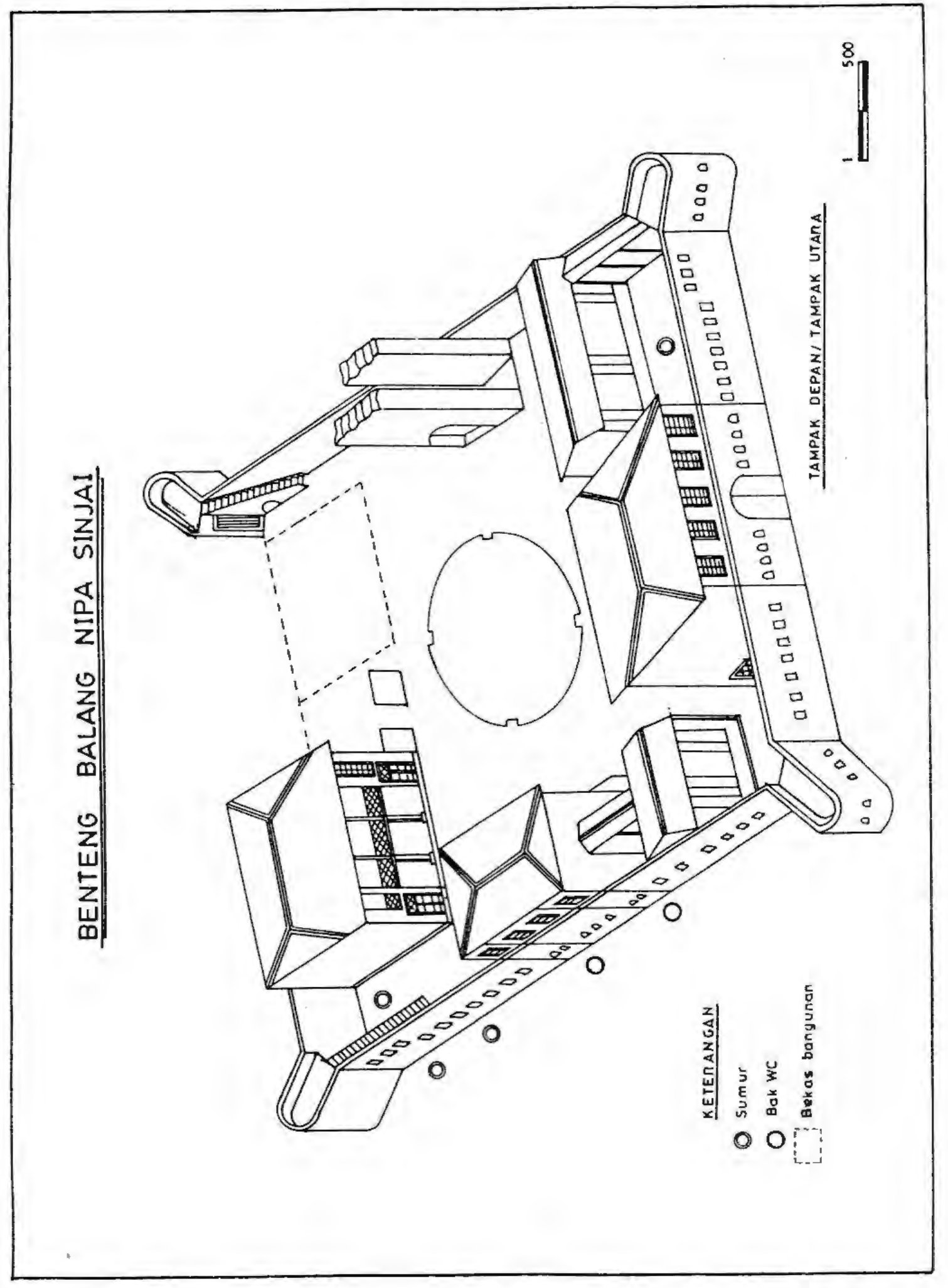

